\title{
Density and distribution of nitrifying guilds in rapid sand filters for drinking water production: Dominance of Nitrospira spp.
}

Tatari, Karolina; Musovic, Sanin; Gülay, Arda; Dechesne, Arnaud; Albrechtsen, Hans-Jørgen; Smets, Barth F.

Published in:

Water Research

Link to article, DOI:

10.1016/j.watres.2017.10.023

Publication date:

2017

Document Version

Peer reviewed version

Link back to DTU Orbit

Citation $(A P A)$ :

Tatari, K., Musovic, S., Gülay, A., Dechesne, A., Albrechtsen, H-J., \& Smets, B. F. (2017). Density and distribution of nitrifying guilds in rapid sand filters for drinking water production: Dominance of Nitrospira spp. Water Research, 127, 239-248. https://doi.org/10.1016/j.watres.2017.10.023

\section{General rights}

Copyright and moral rights for the publications made accessible in the public portal are retained by the authors and/or other copyright owners and it is a condition of accessing publications that users recognise and abide by the legal requirements associated with these rights.

- Users may download and print one copy of any publication from the public portal for the purpose of private study or research.

- You may not further distribute the material or use it for any profit-making activity or commercial gain

- You may freely distribute the URL identifying the publication in the public portal 


\section{Accepted Manuscript}

Density and distribution of nitrifying guilds in rapid sand filters for drinking water production: Dominance of Nitrospira spp.

Karolina Tatari, Sanin Musovic, Arda Gülay, Arnaud Dechesne, Hans-Jørgen Albrechtsen, Barth F. Smets

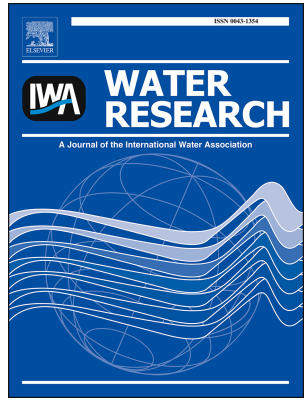

PII: S0043-1354(17)30851-5

DOI: 10.1016/j.watres.2017.10.023

Reference: WR 13280

To appear in: Water Research

Received Date: 20 March 2017

Revised Date: 7 October 2017

Accepted Date: 9 October 2017

Please cite this article as: Tatari, K., Musovic, S., Gülay, A., Dechesne, A., Albrechtsen, Hans.-Jø., Smets, B.F., Density and distribution of nitrifying guilds in rapid sand filters for drinking water production: Dominance of Nitrospira spp., Water Research (2017), doi: 10.1016/j.watres.2017.10.023.

This is a PDF file of an unedited manuscript that has been accepted for publication. As a service to our customers we are providing this early version of the manuscript. The manuscript will undergo copyediting, typesetting, and review of the resulting proof before it is published in its final form. Please note that during the production process errors may be discovered which could affect the content, and all legal disclaimers that apply to the journal pertain. 


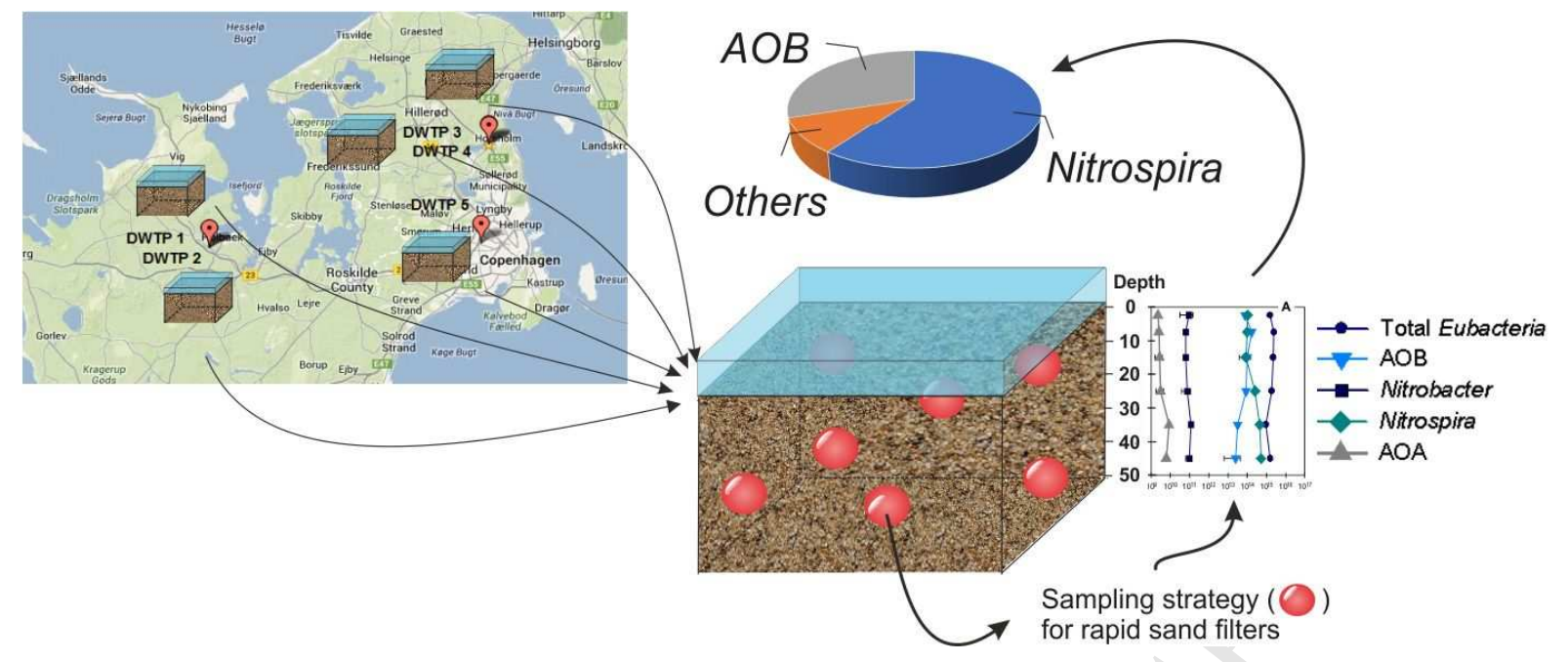




\title{
Density and distribution of nitrifying guilds in rapid sand filters for drinking water production: dominance of Nitrospira spp.
}

\author{
Karolina Tatari ${ }^{\dagger}$, Sanin Musovic ${ }^{\dagger, *}$, Arda Gülay, Arnaud Dechesne, Hans-Jørgen Albrechtsen and \\ Barth F. Smets
}

Department of Environmental Engineering, Technical University of Denmark, Miljøvej 113, 2800 Kgs. Lyngby, Denmark

${ }^{\dagger}$ These authors contributed equally to the manuscript

*Current Affiliation: Danish Technological Institute, Kongsvang Allé 29, Århus 8000, Denmark

Corresponding author: Tel: +45 45252230, E-mail: bfsm@env.dtu.dk (B. F. Smets)

\section{Abstract}

2 We investigated the density and distribution of total bacteria, canonical Ammonia Oxidizing Bacteria (AOB)

3 (Nitrosomonas plus Nitrosospira), Ammonia Oxidizing Archaea (AOA), as well as Nitrobacter and Nitrospira in rapid sand filters used for groundwater treatment. To investigate the spatial distribution of these guilds, filter material was sampled at four drinking water treatment plants (DWTPs) in parallel filters of the pre- and after-filtration stages at different locations and depths. The target guilds were quantified by qPCR targeting 16S rRNA and amoA genes. Total bacterial densities (ignoring 16S rRNA gene copy number variation) were high and ranged from $10^{9}$ to $10^{10}$ per gram $\left(10^{15}\right.$ to $10^{16}$ per $\left.\mathrm{m}^{3}\right)$ of filter material. All examined guilds, except AOA, were stratified at only one of the four DWTPs. Densities varied spatially within filter (intra-filter variation) at two of the DWTPs and in parallel filters (inter-filter variation) at one of the DWTPs. Variation analysis revealed random sampling as the most efficient strategy to yield accurate mean density estimates, with collection of at least 7 samples suggested to obtain an acceptable (below half 
total community), and was generally up to 4 orders of magnitude more abundant than Nitrobacter and up to 2 orders of magnitude more abundant than canonical AOBs. These results, supplemented with further analysis of the previously reported diversity of Nitrospira in the studied DWTPs based on $16 \mathrm{~S}$ rRNA and $n x r B$ gene phylogeny (Gülay et al., 2016; Palomo et al., 2016), indicate that the high Nitrospira abundance is due to their comammox (complete ammonia oxidation) physiology. AOA densities were lower than AOB densities, except in the highly stratified filters, where they were of similar abundance. In conclusion, rapid sand filters are microbially dense, with varying degrees of spatial heterogeneity, which requires replicate sampling for a sufficiently precise determination of total microbial community and specific population densities. A consistently high Nitrospira to bacterial and archaeal AOB density ratio suggests that non-canonical pathways for nitrification may dominate the examined RSFs.

\section{Keywords}

RSF, nitrifying guilds, AOB, NOB, AOA, comammox, Nitrospira

\section{Introduction}

Rapid sand filters (RSFs) are widely used in groundwater treatment to remove compounds like $\mathrm{NH}_{4}{ }^{+}, \mathrm{Fe}^{2+}$ and $\mathrm{Mn}^{2+}$ to below drinking water quality standards; removal occurs by a combination of physico-chemical and biochemical means. The maximum allowed $\mathrm{NH}_{4}{ }^{+}$(and $\mathrm{NO}_{2}{ }^{-}$) concentration in the effluent from the drinking water treatment plants (DWTPs) in Europe is $0.5 \mathrm{mg} / \mathrm{L}$ (and $0.1 \mathrm{mg} / \mathrm{L}$ ) (Council Directive 98/93/EC 1998), unless stricter limits are applied by the individual member states (e.g. $0.05 \mathrm{mg} / \mathrm{l}$ (and $0.01 \mathrm{mg} / \mathrm{L}$ ) in DK). $\mathrm{NH}_{4}^{+}$residuals in non-chlorinated systems can cause $\mathrm{O}_{2}$ consumption in the distribution network (Zhang et al. 2009), as well as accumulation of toxic $\mathrm{NO}_{2}{ }^{-}$due to incomplete nitrification (Lytle et al. 2007). In chlorinated distribution systems, $\mathrm{NH}_{4}{ }^{+}$removal is important to control the chlorine residuals and avoid the formation of disinfection byproducts (Lytle et al. 2013, Rittmann et al. 2012). 
$\mathrm{NH}_{4}{ }^{+}$removal in RSFs has been assumed to be a two-step biological oxidation process, first to $\mathrm{NO}_{2}{ }^{-}$and then to $\mathrm{NO}_{3}{ }^{-}$. Oxidation to $\mathrm{NO}_{2}^{-}$has typically been attributed to canonical Ammonia Oxidizing Bacteria (AOB) such as Nitrosomonas and Nitrosospira and Ammonia Oxidizing Archaea (AOA); both AO types have been identified in biological filters (Bai et al. 2013, de Vet et al. 2011, Tatari et al. 2016), although their relative contribution to $\mathrm{NH}_{4}^{+}$removal in these engineered systems has not yet been examined. AOB predominance over AOA seems to link with the $\mathrm{NH}_{4}{ }^{+}$concentration, with lower concentrations favoring the predominance of AOA, potentially due to their higher affinity for $\mathrm{NH}_{4}{ }^{+}$(Martens-Habbena et al., 2009; Niu et al., 2013; Sauder et al., 2012). $\mathrm{NO}_{2}^{-}$oxidation in RSFs has been attributed to Nitrospira and Nitrobacter, although Nitrospira has been detected at much higher densities compared to Nitrobacter (Albers et al. 2015, Tatari et al. 2016). Additionally, Nitrospira but not Nitrobacter were detected in a trickling filter treating groundwater (de Vet et al. 2009).

Few studies have reported on densities of different nitrifying guilds, yet such information might provide clues on the importance of different guilds in the overall RSF performance (i.e. ammonia removal) under certain operational conditions. In trickling filters treating groundwater, mean filter densities of AOB $\left(10^{7}-10^{9}\right.$ AOB cells /g filter material) vastly exceeded those of AOA $\left(10^{5}\right.$ cells /g filter material) as quantified by amoA-based qPCR (de Vet et al. 2009). AOB mean densities of $10^{6}-10^{9}$ copies/g filter material were reported (quantified by amoA-based qPCR) for granular activated carbon filters treating surface water (Niu et al. 2013). The large range in reported densities (for single systems) would seem worrying, yet quantification of total bacteria, $\mathrm{AOB}$ and $\mathrm{AOA}$ in biological sand filters has occasionally revealed substantial depth stratification and spatial variation (Bai et al. 2013, Lee et al. 2014, Tatari et al. 2016, Gülay et al., 2016). Hence, appropriate sampling may be essential to ensure representative density estimates of microbial guilds in RSFs.

Relative densities of different microbial guilds can also be compared to predicted ratios based on assumed physiology and stoichiometry; large deviations would then challenge the underlying assumptions. Recently we discovered anomalous relative densities Nitrospira to AOB in RSFs, with Nitrospira comprising up to $45 \%$ of all community $16 \mathrm{~S}$ rRNA gene amplicons with canonical AOB attaining on average $2.5 \%$ (Gülay et 
al., 2016). These unexpectedly high Nitrospira densities do not agree with stoichiometry assuming Nitrospira to have physiology of a nitrite oxidizing bacterium (NOB), which would predict ratios of AOB to NOB of 2 to 3 (Hagopian and Riley 1998, Winkler et al. 2012). Recently, some Nitrospira types have been found to carry a full set of amo and hao genes, which may enable them to oxidize also $\mathrm{NH}_{4}{ }^{+}$and therefore carry out complete $\mathrm{NH}_{4}{ }^{+}$(to $\mathrm{NO}_{3}{ }^{-}$) oxidation; all amo containing Nitrospira described to date belong to Nitrospira sublineage II (Daims et al. 2015, Palomo et al. 2016, van Kessel et al. 2015, Pinto et al., 2015). Nevertheless, direct proof for $\mathrm{NH}_{4}{ }^{+}$oxidizing activity by Nitrospira in RSFs has not yet been provided.

This work addressed the following questions. First, is there significant spatial variation in the distribution of total bacteria and nitrifying guilds (AOB, AOA, Nitrobacter and Nitrospira) in RSFs? Second, do the relative densities of the nitrifying guilds agree with their expected roles and physiologies in RSFs? Hence, we conducted an extensive and spatially explicit survey of nitrifying guilds in replicate filters at 4 DWTPs. The data were used to examine spatial variation, and identify optimal sampling strategies. Relative density ratios were examined and related to the operating conditions to infer roles of the different guild members. Finally, given the consistently high Nitrospira presence, we assessed the relative abundance of Nitrospira sublineages based on $n x r B$ and $16 \mathrm{~S}$ rRNA gene analysis.

\section{Materials \& Methods}

\subsection{Overview of the investigated DWTPs}

The investigations included four Danish DWTPs treating groundwater that have been in operation for 6 to 40 years. Groundwater at the investigated DWTPs is abstracted from deep limestone anoxic aquifers and the treatment train consists of an aeration step and a double filtration step. Pre-filters have a bed of coarse sand material and are intended to retain the Fe-hydroxides, formed by the oxidation of $\mathrm{Fe}^{2+}$. Pre-filter effluent is supplied to the after-filters, which consists of a 0.4 to $0.7 \mathrm{~m}$ deep bed of fine sand on top of gravel. Design parameters and selected water quality characteristics at the investigated DWTPs are summarized in Table 1. Pre- and after-filters at the investigated DWTPs are backwashed at regular times by air scouring followed by high water flowrates (Table 1). 
DWTP 1 and 2 are located at Sjælsø (Nordvand A/S), in the greater Copenhagen area. The two DWTPs are operated independently and receive raw water with significantly different $\mathrm{CH}_{4}$ content (Table 1). DWTP 3 (Langerød) is located in Holbæk (Fors A/S) and consists of two parallel lines, West and East (W, E) which were operated nearly identically, but displayed different performance with regards to $\mathrm{NH}_{4}{ }^{+}$removal (effluent $\mathrm{NH}_{4}{ }^{+}$concentration 0.05 and $0.15 \mathrm{mg} / \mathrm{L}$ from E and $\mathrm{W}$, respectively). DWTP 4 is Islevbro waterworks (HOFOR A/S) located in the greater Copenhagen area, and has very low $\mathrm{NH}_{4}{ }^{+}$and $\mathrm{CH}_{4}$ concentrations in the raw water (Table 1).

\subsection{Filter material sampling}

Microbial density was quantified for filter material collected from the pre- and after-filters at the investigated DWTPs. The sampling strategy was designed to investigate depth stratification, spatial variation within a filter (intra-filter variation) and variation between parallel filters (inter-filter variation). Filter material was core-sampled using a Plexiglas cylinder (1 $\mathrm{m}$ height and $5 \mathrm{~cm}$ inner diameter), closed on the one end with a rubber stopper. The sampler was pushed into the filter and gently pulled retaining a 40-60 cm filter material core. One pre-filter was sampled at 1-3 random locations at DWTPs 1-3. The pre-filters at DWTP 4 could not be sampled because of the coarse filter material (Table 1) that could not be collected with the core sampler. 2-3 parallel after-filters were sampled at all DWTPs, and a filter material core was collected from 13 randomly selected locations in each filter. All cores were sampled at approximately $2 / 3$ of a filter run cycle between two consecutive backwashing events. The filter material cores were divided into the following depth segments: $0-5,5-10,10-20,20-30,30-40,40-50 \mathrm{~cm}$ that were transferred to the lab on ice and frozen until further analysis.

\subsection{Quantification of the selected microbial guilds by qPCR}

The density of total bacteria (Eubacteria), $\beta$-proteobacterial AOB (Nitrosomonas spp and Nitrosospira spp), Nitrobacter spp, and Nitrospira spp was quantified by $16 \mathrm{~S}$ rRNA gene targeted qPCR in each filter material segment. DNA was extracted from $0.5 \mathrm{~g}$ drained filter material using MP FastDNA SPIN Kit (MP Biomedicals LLC) previously shown effective for DNA extraction from iron oxide rich environments (Kato et al. 2013). Earlier efforts at removing/solubilizing metal oxides by pretreatment with oxalic acid did not 
enhance DNA recovery, and neither did pretreatment by sonication. The extracted DNA was eluted in $100 \mu \mathrm{l}$ Tris-EDTA buffer and its concentration and purity estimated by measuring absorbance at 260 and $280 \mathrm{~nm}$ (NanoDrop). A group specific region on the 16S ribosomal-RNA encoding the rrs gene (16S rRNA) was targeted by the primer sets 1055f and 1392R for total bacteria (Ferris et al. 1996, Lane 1991), CTO189A/B/C and RT1 for $\beta$-proteobacterial AOB genera Nitrosomonas and Nitrosospira (Hermansson and Lindgren 2001), Nspra675f and Nspra746r for the Nitrospira genus (Graham et al. 2007) and FGPS872f and FGPS1269r for the Nitrobacter genus (Degrange and Bardin 1995). AOB and AOA were also quantified by amoA targeted $\mathrm{qPCR}$, using the amoA1f and amoA2r primers for $\beta$-proteobacterial AOB (Rotthauwe et al. 1997) and the amoAF and amoAR primers for AOA (Francis et al. 2005). Specificity of the 16S rRNA and amoA targeted primers for beta-proteobacterial AOB was confirmed and published separately (Dechesne et al., 2016); specificity of the amoA targeted primers for AOA was confirmed here by clone library analysis; the 16S rRNA targeted primers for Nitrospira were confirmed post hoc by in silico comparison with the $16 \mathrm{~S}$ rRNA amplicon libraries of the same samples (Gülay et al. 2016) to be specific and cover $96 \%$ cover of all Nitrospira diversity.

The qPCR analyses were run in duplicate in a Chromo4 thermocycler using the Opticon Monitor 3 software (Bio-Rad Laboratories). Each qPCR reaction contained $12.5 \mu$ of 2xiQ SYBR Green Supermix (Bio-Rad Laboratories), $500 \mathrm{nM}$ of each primer, DNA template (10 ng) and DNA/RNA-free water (Mol. Bio.) to 25 $\mu 1$. The thermal cycling conditions consisted of an initial 5 min denaturation at $95^{\circ} \mathrm{C}$, followed by 40 cycles of $30 \mathrm{~s}$ at $94^{\circ} \mathrm{C}$, primer annealing for $30 \mathrm{~s}$ at $55^{\circ} \mathrm{C}$ for total bacteria, $30 \mathrm{~s}$ at $60 / 56^{\circ} \mathrm{C}$ for $\mathrm{AOB}$ (16S-rRNA), $60 \mathrm{~s}$ at $50^{\circ} \mathrm{C}$ for Nitrobacter, $30 \mathrm{~s}$ at $64^{\circ} \mathrm{C}$ for Nitrospira, $60 \mathrm{~s}$ at $60^{\circ} \mathrm{C}$ for $\mathrm{AOA}\left(\right.$ amoA), $40 \mathrm{~s}$ at $55^{\circ} \mathrm{C}$ for $\mathrm{AOB}(\operatorname{amoA})$, and 1 min extension at $72^{\circ} \mathrm{C}$. After the $40^{\text {th }}$ cycle, a final DNA extension at $72^{\circ} \mathrm{C}$ for $10 \mathrm{~min}$ was performed followed by cooling at $4^{\circ} \mathrm{C}$. The melting curve analysis (gradient $0.2^{\circ} \mathrm{C} / \mathrm{s}$, range $70-95^{\circ} \mathrm{C}$ ) (Ririe et al. 1997) showed single peaks for all qPCR reactions. Reported qPCR reactions had amplification efficiencies between 97 and 100\%; addition of BSA (to address potential PCR inhibition) had no further positive effect. The gene copy number was obtained by comparing the cycle threshold values of the sample 
140

against a standard curve for each qPCR target. To express microbial densities per unit volume of filter material, bulk densities at each depth were calculated by weighing $10-20 \mathrm{~mL}$ of drained filter material.

\subsection{Statistical analysis of microbial densities}

The measured densities in pre- and after-filters were statistically analyzed to assess their spatial variation at three levels: depth stratification, intra-filter variation and inter-filter variation. Spearman's rank correlation tests $(\alpha=0.05)$ were performed to examine the correlation between density of a specific guild and filter depth. To investigate intra-filter variation, the depth profiles from distinct locations in a filter were tested for differences by paired t-tests $(\alpha=0.05)$ in all possible combinations. Lastly, inter-filter variation was investigated by paired t-tests $(\alpha=0.05)$ on mean depth profiles in parallel filters. The mean depth profile in a filter was calculated as the mean density at each depth for all sampling locations.

To assess how the sampling effort relates to the measured average density of a specific guild, we examined the distribution of the total bacterial mean density in the after-filters. This analysis examined three sampling strategies: random sampling, sampling at different depths and sampling at different locations. Detailed information about statistical analyses is provided in the Supplemental Information (SI).

\subsection{Bioinformatic analysis}

We evaluated the lineages that constitute the comammox Nitrospira population genome CG24 earlier identified in DWTP 4 (Palomo et al., 2016) and the Nitrospira distribution across its lineages at all DWTPs based on earlier published 16S rRNA amplicon libraries (Gülay et al., 2016). Details on bioinformatics analysis are in the SI.

\section{Results \& Discussion}

\subsection{Density of total bacteria, AOB, Nitrobacter, Nitrospira and AOA in RSFs}

The targeted microbial guilds were quantified by qPCR in the filter material collected from the pre- and after-filters. Filter material density and microbial density values are reported (Table 2) as means of the 
densities at all depths, all sampled locations and all parallel filters for each filtration stage at each DWTP. The mean filter material densities were in the range of $1.0-1.7 \times 10^{6} \mathrm{~g} / \mathrm{m}^{3}$ (Table 2), with variation caused by the different filter material types and sizes (Table 1) and degrees of mineral coating (Gülay et al. 2014).

Microbial densities, measured per unit filter material mass, are readily converted into volume using the estimated filter material densities. While both density expressions are presented (Table 2) for the examined guilds, the following discussion considers volumetric densities.

Total bacterial (Eubacteria) 16S rRNA gene densities ranged from 1.1 to $16 \times 10^{15}$ copies $/ \mathrm{m}^{3}$ filter material (Table 2). The density was highest in the pre-filters at DWTP 2, and was substantially higher than the density in the after-filters at the same DWTP (Table 2). At the other investigated DWTPs, bacterial density was similar in pre- and after-filters (Table 2). The high density observed in the pre-filters is surprising, as prefilters were historically thought to remove primarily $\mathrm{Fe}^{2+}$ and mainly through chemical oxidation and precipitation (Sharma et al., 2005). It appears that the resulting oxy-hydroxide precipitates provide a highlyporous mineral coating on the filter grains, which can support the high microbial density (Gülay et al., 2014).

Canonical AOB (Nitrosomonas spp. and Nitrosospira spp.) were identified in all investigated filters at $16 \mathrm{~S}$ rRNA gene densities ranging from 0.5 to $35 \times 10^{13}$ copies $/ \mathrm{m}^{3}$ filter material. Densities in the pre-filters were higher than in the after-filters at all DWTPs, with one exception (DWTP 3-E, Table 2). High AOB densities in the pre-filters indicate that $\mathrm{NH}_{4}^{+}$removal takes place in both filtration steps. For example, at DWTP 3 the $\mathrm{NH}_{4}{ }^{+}$concentrations after aeration were $0.89-0.94 \mathrm{mg} / \mathrm{L}$ and decreased to $0.54-0.75$ after the prefilters and further to $0.007-0.1 \mathrm{mg} / \mathrm{L}$ after the after filters. This waterworks (DWTP 3) had different nitrification behaviors in the parallel lines: DWTP $3-\mathrm{W}$ consistently removed $\mathrm{NH}_{4}{ }^{+}-\mathrm{N}$ more efficiently and to a lower level (e.g. 0.007-0.01 mg/L) than DWPT3-E (e.g. 0.077-0.11 mg/L), which is reflected by a higher AOB density (particularly in the prefilters) in DWTP 3-W than in DWTP 3-E (Table 2).

Nitrobacter 16S rRNA gene densities ranged across two orders of magnitude: from 3.6 to $500 \times 10^{10}$ copies $/ \mathrm{m}^{3}$ in the investigated filters (Table 2). Nitrobacter pre-filter densities were higher than the respective after-filter densities at all DWTPs. Nitrospira were present in all investigated filters at 16S rRNA gene 
densities ranging from 0.97 to $33 \times 10^{14}$ copies $/ \mathrm{m}^{3}$ filter material. Nitrospira densities at two waterworks (DWTPs 1 and 2) were slightly (4 to 6 fold) higher in pre-filter versus after-filters, with the opposite trend in a third waterworks (DWTP 3, Table 2). Consistently, Nitrospira densities were at least 2 orders of magnitude higher than Nitrobacter densities, suggesting Nitrospira as dominant $\mathrm{NO}_{2}{ }^{-}$oxidizer at all DWTPs. Another study on Danish DWTPs reports that Nitrospira accounted for up to $8 \%$ of all prokaryotic amplicon sequences and detected no Nitrobacter sequences in RSFs (Albers et al. 2015); however the lack of replication and the exceedingly small amplicon library size (558 sequences/samples) challenge the robustness of those observations. Similarly Nitrospira, but not Nitrobacter, were detected by DGGE analysis of 16S rRNA gene fragments from a groundwater fed trickling filter (de Vet et al. 2009). Nitrospira sequences also accounted for up to $51 \%$ of the clone library in samples from an anthracite/sand dual media filter fed with groundwater (White et al. 2012). Finally, in our microbial community diversity analysis on the same DWTPs, we similarly observed Nitrospira sp. as the most abundant taxon in the 16S rRNA amplicon libraries (from 19\% to $71 \%$ in all DWTPs (Gülay et al., 2016)).

AOA amoA gene densities were below detection limits in one of the after-filters (DWTP 3), while at the other waterworks their densities ranged from 4.0 and $20 \times 10^{9}$ copies $/ \mathrm{m}^{3}$ filter material. AOA were typically 4 orders of magnitude less abundant than AOBs, except in the DWTP 4 after-filters, where highest AOA densities were observed (Table 2).

Overall, RSF are microbially dense, and the targeted guilds are often at least as heavily present in the prefilters as in the after-filters, revealing an important role of pre-filters in biological processes.

\subsection{Spatial distribution of the investigated microbial guilds}

In the pre-filters, limited stratification was observed (except in DWTP 2, where AOB and Nitrospira densities decreased with depth and in DWTP 1 where Nitrospira densities increased with depth (Fig 1, Table SI 1)). Stratification in the after-filters was noted for some microbial guilds at DWTP 2 and 3, and for all microbial guilds (except AOA) at DWTP 4 (Fig. 1, Table SI 2), with densities decreasing with depth. No stratification was observed in the after-filters at DWTP 1 (Fig. 1). 
Backwashing frequency and strategy are crucial to control the mixing and redistribution of the filter material, eventually preventing or allowing permanent stratification in the filter. Stratification at DWTP 3 and 4 is maintained after backwashing due to the presence of substantial mineral coatings on the filter material grains, which forces larger - and less dense grains - to remain at the top of the filter, and smaller - denser grains - to settle in deeper filter regions, thus maintaining a permanent distribution (Gülay et al. 2014). In line with these observations, sand grains in DWTP 1 and 2 have a very low degree of mineral coating at all depth levels and show no evidence of biomass stratification (Gülay et al. 2014). Depth stratification in groundwater-fed periodically backwashed RSFs has been observed before (Bai et al. 2013).

In individual pre-filters, replicate profiles at different sampling locations yielded essentially similar density distributions for all microbial populations (except for Nitrobacter (Table SI 3)) and the same was observed in the after-filters (Table SI 4). This stands in contrast to previous studies (at DWTP 1) which documented local hydraulic heterogeneity in both pre- and after-filters, and suggested a strong effect on local $\mathrm{NH}_{4}{ }^{+}$removal rate (Lopato et al. 2011, Lopato et al. 2013). Clearly, the hydraulic heterogeneity does not result in observable differences in horizontal densities of microbial groups.

However, parallel after-filters at a DWTP often had different profiles: densities of total bacteria, AOB and Nitrospira varied across the filters of both lines at DWTP 3, whereas 50\% of the compared profiles were significantly different at DWTP 4 and no significant variation was observed at DWTP 1 and 2 (Tables SI 57). Inter-filter variation at both lines of DWTP 3 was much larger than the intra-filter variation, and the opposite was observed at DWTPs 1 and 2. Hence, spatial variation of the targeted guilds does not follow a predictable pattern at the investigated DWTPs.

\subsection{Investigation of mean density precision and required sampling effort}

The increase in precision of the estimated mean density was evaluated as a function of sampling effort and sampling strategy ((i) random sampling of $s$ samples across locations, parallel filters, and depth; (ii) sampling all locations for $d$ randomly chosen depths; (iii) and sampling full profiles at $l$ randomly chosen locations). Setting half-an-order of magnitude as an acceptable precision, the mean density and associated precision 
were computed at the investigated DWTPs: clearly precision increased with increasing sampling effort (Fig.

2, Fig. SI 1). With DWTP 4 as an example, sampling at 7 random combinations of locations and depths was required to meet the demanded precision (Fig. 2). Sampling at different depths would require 14 samples (2 randomly chosen depths at all investigated filter locations and parallel filters), sampling at different locations and filters would require 17 samples (at least 3 locations, each location sampled at 5-6 depths). Clearly random sampling yielded an acceptably precise density estimate with lowest effort, and there was no advantage of exhaustively sampling depths profiles or horizontal profiles.

The mean bacterial density estimates were more precise at DWTPs 1-3, where collection of a singular sample would already give an estimate within half-an-order of magnitude precision (Fig. SI 1). For almost all DWTPs, random sampling yields the highest precision compared to sampling at different depths or locations (Fig. SI 1). The only exception was at DWTP 3-W, where sampling of 1 filter location at all depths (7 samples) yields a higher precision than collecting 7 random samples (Fig. SI 1). However, fewer than 7 samples are required to obtain a mean precision above the acceptable limit of half-an-order of magnitude.

Overall, the mean density precision can vary significantly at different DWTPs. In all cases random sampling across filters, filter locations and depths yielded the highest precision for a given number of samples. According to the precision required by each study, the number of samples needed may vary significantly. In this study, each sample had a mass of 100-333 g drained filter material, depending on the depth interval (segmented every 5 or $10 \mathrm{~cm}$ as described in sec. 2.2) and the bulk density. Ultimately, 7 samples randomly collected should generally be sufficient to provide a precision of the mean of half order of magnitude, even at DWTPs with heterogeneous microbial spatial distributions. Our recommendations apply to density, but may not apply to community diversity or composition. When the same samples were subject to community analysis via 16S rRNA amplicon sequencing, triplicate samples within a RSF were compositionally different from each other at the whole community level (Gülay et al., 2016); yet were identical in terms of dominant taxa (>1\%) (Gülay and Smets, 2015). 
263

264

265

\subsection{Relative abundance of microbial guilds}

The fraction of canonical AOB (abundance vs total bacteria) ranged from 0.004 and 0.07 in the pre-filters, and from 0.002 and 0.12 in the after-filters (Fig. 3, Panels A and D). Abundances in the pre- and after-filters were similar at most DWTPs except at DWTP 1, where abundance in the pre-filters was approximately one order of magnitude higher than in the after-filters. No patterns were observed with depth.

The ratio of canonical AOB to Nitrospira ranged from 0.02 and 1.9 in the pre-filters, and from 0.04 and 0.6 in the after-filters (Fig. 3, Panels B and D). Ratios were consistently below 1 in all RSFs except in one set of pre-filters (DWTP 1), where AOB were more dominant than Nitrospira in the filter top (ratio 1.9). Even here, an increase in Nitrospira density with depth (Table SI 1) made AOB less dominant than Nitrospira at the bottom of the filter (ratio 0.05). Overall, while the proportions varied, canonical AOB (i.e. Nitrosomonas plus Nitrosospira genus) were consistently less abundant than Nitrospira genus.

Similar anomalous Nitrospira to Nitrosomonas (or more correctly Nitrosomonas + Nitrosospira) abundance ratios have been reported by others. These reports were based on relative sequence abundances in clone or amplicon libraries in both groundwater (e.g. 3.7\% vs 33.4\% (Nitzsche et al. 2015); 3.2\% vs 16.9\% (White et al. 2012) Nitrosomonas and Nitrospira abundance, respectively) and surface water fed drinking water treatment gravity filters (0.8\% vs $17.3 \%$ (Feng et al. 2012), $0.07 \%$ vs 17 Nitrosomonas and Nitrospira abundance, respectively (LaPara et al. 2015)). Proposed, yet unproven, explanations for these observations were PCR primer bias, differences in 16S rRNA gene copy numbers (Nitzsche et al. 2015), presence of unidentified $\mathrm{NH}_{4}{ }^{+}$oxidizers (LaPara et al. 2015) and presence of dormant Nitrospira cells (Martiny et al. 2005). Winkler et al. (2012) proposed that unexpectedly high $\mathrm{NO}_{2}{ }^{-}$oxidizer (e.g. Nitrospira) abundance in a community may also be caused by a $\mathrm{NO}_{2}^{-}$oxidation $/ \mathrm{NO}_{3}^{-}$reduction loop, which would be driven by incomplete heterotrophic denitrification. While bulk phase dissolved oxygen concentrations in both pre- and after-filters are near saturation, strictly heterotrophic anaerobes (Xanthomonadales and Anaerolineales) have been reported in amplicon libraries of the after-filters (Gülay et al., 2016), and existence of the proposed $\mathrm{NO}_{2}{ }^{-} / \mathrm{NO}_{3}{ }^{-}$loop, and its contribution to the observed Nitrospira abundance should be examined. 
Recent discoveries have revealed that the physiological abilities of Nitrospira may extend far beyond $\mathrm{NO}_{2}{ }^{-}$ oxidation. Genomic and physiological evidence has shown that certain Nitrospira strains can oxidize hydrogen, cyanate and simple organic compounds such as formate (Koch et al., 2014) (Palatinszky et al., 2015). The chemical nature of the groundwater and the initial aeration/stripping makes cyanate or hydrogen unlikely candidates to support Nitrospira growth, especially in the downflow units. Similarly, because assimilable organic carbon in the feed groundwater is low, only decay products from the RSF microbiome would be available to support heterotrophic Nitrospira growth. The qPCR results, and our previous 454 survey (Gülay et al., 2016), indicate that Nitrospira is the most abundant taxon: such abundance is not likely supported by metabolic decay products of a microbial community. Of specific interest is the recent discovery that some Nitrospira genomes harbor amo genes and have the potential for $\mathrm{NH}_{4}{ }^{+}$oxidation - in addition to $\mathrm{NO}_{2}{ }^{-}$oxidation - endowing them the physiology of complete ammonia oxidation (comammox) (Daims et al., 2015; Palomo et al., 2016; Pinto et al., 2015; van Kessel et al., 2015). The described enriched and isolated comammox Nitrospira strains - Candidatus Nitrospira inopinata, Cand N. nitrosa and Cand. N. nitrificans (Daims et al., 2015)(van Kessel et al., 2015) - all belong to Nitrospira lineage II, with N. moscoviensis as best known canonical NOB as reference strain (Pester et al., 2014).

Given the striking dominance of the Nitrospira genus in all DWTPs (Fig. 1, Table 2), we analyzed its composition across Nitrospira lineages from the 16S rRNA amplicon libraries at the same DWTPs (Gülay et al., 2016): Nitrospira lineage II dominated at all DWTPs, representing consistently over 95\%, with not-yetnamed lineages accounting for 3.5\% \pm 0.03 , of all Nitrospira reads (Fig. 4 Fig SI 2, Table SI 8).

Earlier, we identified, from the DWTP 4 metagenome, a Nitrospira population genome with comammox capability (CG_24) (Palomo et al., 2016). This population genome consisted of several sub-genomes, but no efforts were made to separate the individual genomes and examine their phylogeny. Here - based on phylogenetic analysis of CG24's nxrB content - we show that the five different constituent $n x r B$ sequence types are lineage II (Fig. 4). As nxrB and 16S rRNA genes yield congruent Nitrospira phylogenies (Pester et al., 2014), and given the high abundance of CG24 in the community metagenome (up to $30 \%$ of all mapped reads (Palomo et al., 2016)); Nitrospira in DWTP 4 are likely primarily comammox Nitrospira. By 
extension, these results indicates that the high Nitrospira abundances (compared to canonical AOBs) in all examined DWTPs are, to a large extent, the result of the $\mathrm{NH}_{4}{ }^{+}$oxidation capability of Nitrospira.

AOA were consistently less abundant than AOB (based on amoA targeted qPCR) in both pre- and afterfilters at DWTPs 1, 2, and 3, (Fig. 3, Panels C and F) and occasionally at or below detection limit. AOA have been identified in other drinking water treatment plants - where occasionally they are abundant (Kasuga et al., 2010; van der Wielen et al., 2009). When detected in this study, the AOA/AOB ratios ranged between $3 \times 10^{-6}$ and $8 \times 10^{-3}$ in the pre-filters, and between $2 \times 10^{-5}$ and 0.2 in the after-filters. While the AOA/AOB ratios were calculated based on archaeal and bacterial amoA targeted qPCR, quantification based on the chosen amoA PCR primers (Rotthauwe et al. 1997) underestimates AOB densities (based on 16S rRNA targeted qPCR) at some DWTPs (DWTPs 1, 2 and 4 but not at DWTP 3 (Fig. SI 3)). This underestimation was recently identified as caused by the preferential amplification of amoA Cluster 7 vs. Cluster $6 \mathrm{~A}$ AOBs (Dechesne et al. 2016). In addition, the employed amoA primers would not quantify comammox amoA (Daims et al. 2015). Considering this bias, the AOA to AOB ratios at DWTPs 1 and 2 would be even lower. No consistent trend of the AOA/AOB ratio with depth was observed at any of these DWTPs. AOAs were at significant abundance compared to AOB in only one of the waterworks (DWTP 4) (AOA/AOB from 0.26 in the top $0-5 \mathrm{~cm}$ to 20 at the bottom $40-50 \mathrm{~cm}$ (Fig. 3, Panel F)). The increased ratio (by roughly 2 orders of magnitude) was mainly due a reduction in AOB abundance (Fig. 1, Panel C) and may suggest a significant role of AOA at the bottom of the filter. Yet, as amoA based qPCR also underestimates AOB densities at DWTP 4 (Fig SI 3), the true ratios are higher and AOA may have a secondary role even at the bottom of the filter at DWTP 4. The relative enrichment of AOA over AOB at the filter base (with lower $\mathrm{NH}_{4}^{+}$supply) is, nevertheless, consistent with the notion that AOA are competitive over AOB in conditions of reduced energy supply, such as in soils (Leininger et al. 2006, Verhamme et al. 2011) and ocean (Wuchter et al. 2006), most likely due to their ability to cope with energy stress (Martens-Habbena et al. 2009, Valentine 2007). At the system level, similar correlations between $\mathrm{AOA}$ and $\mathrm{AOB}$ predominance and $\mathrm{NH}_{4}{ }^{+}$loading are apparent, with $\mathrm{AOB}$ densities (in both pre- and after-filters) increasing with loadings, and AOA densities decreasing 
with loading (Fig. 5) consistent with observations that AOA densities increase inversely with ammonium gradients (Sauder et al., 2012).

In sum, notwithstanding the relatively low influent ammonium concentrations (max. $1 \mathrm{mg} / \mathrm{L}$ ) at all DWTPs canonical AOB are numerically dominant over AOA, and both are vastly inferior to Nitrospira.

\section{Conclusions}

This work presents the first comprehensive investigation of the density and spatial distribution of total bacteria, AOB, Nitrobacter, Nitrospira and AOA by qPCR at a number of full scale DWTPs. The main conclusions are:

- Microbial density can vary spatially in a filter and in parallel filters at a DWTP. Specifically, we observed strong stratification of nitrifying guilds in one DWTP, but not in others. Horizontally, intraor/and inter filter variation were significant at the investigated DWTPs, indicating the need of proper experimental design to obtain representative results.

- Variation analysis for total bacteria estimated that 7 random filter material samples need to be collected at a DWTP with high spatial variation to obtain an acceptable precision for the mean (half an order of magnitude). At the other investigated DWTPs, one sample collected from a random location can already provide a density estimate within an acceptable (half an order of magnitude) precision interval. Higher sample replication will typically be required if the goal is to describe mean microbial community composition (Gulay et al, 2016)

- Nitrospira were roughly 4 orders of magnitude more abundant than Nitrobacter in all investigated filters, suggesting that they should be the predominant $\mathrm{NO}_{2}{ }^{-}$oxidizers. Yet, Nitrospira were also up to almost 2 orders of magnitude more abundant than AOBs, and we suggest that the Nitrospira abundance is primarily caused by their $\mathrm{NH}_{4}{ }^{+}$oxidation capability (comammox). 
- Among the canonical ammonia oxidizers, AOB exceed AOAs in RSFs, except in RSFs with strong stratification; and AOB are favored at DWTPs operating at higher loading rates.

\section{Acknowledgments}

We thank Florian Wagner for assistance in preparing Table 1 and providing valuable feedback on the manuscript. This work was supported by the Danish Council for Strategic Research (Grant agreement number: KBBE- 2012-6-311846) via the project DW-Biofilters.

\section{References}

Albers, C.N., Ellegaard-Jensen, L., Harder, C.B., Rosendahl, S., Knudsen, B.E., Ekelund, F. and Aamand, J. (2015) Groundwater chemistry determines the prokaryotic community structure of waterworks sand filters. Environmental Science \& Technology 49(2), 839-846.

Bai, Y., Liu, R., Liang, J. and Qu, J. (2013) Integrated metagenomic and physiochemical analyses to evaluate the potential role of microbes in the sand filter of a drinking water treatment system. Plos One 8(4).

Council Directive 98/93/EC (1998) Quality of Water Intended for Human Consumption, Annex I, Part C.

Daims, H., Lebedeva, E.V., Pjevac, P., Han, P., Herbold, C., Albertsen, M., Jehmlich, N., Palatinszky, M., Vierheilig, J., Bulaev, A., Kirkegaard, R.H., von Bergen, M., Rattei, T., Bendinger, B., Nielsen, P.H. and Wagner, M. (2015) Complete nitrification by Nitrospira bacteria. Nature 528(7583), 504-+.

de Vet, W., Dinkla, I.J.T., Muyzer, G., Rietveld, L.C. and van Loosdrecht, M.C.M. (2009) Molecular characterization of microbial populations in groundwater sources and sand filters for drinking water production. Water Research 43(1), 182-194. 
de Vet, W., Kleerebezem, R., van der Wielen, P., Rietveld, L.C. and van Loosdrecht, M.C.M. (2011) Assessment of nitrification in groundwater filters for drinking water production by qPCR and activity measurement. Water Research 45(13), 4008-4018.

Dechesne, A., Musovic, S., Palomo, A., Diwan, V. and Smets, B.F. (2016) Underestimation of ammoniaoxidizing bacteria abundance by amplification bias in amoA-targeted qPCR. Microbial Biotechnology 9(4), $519-524$.

Degrange, V. and Bardin, R. (1995) Detection and counting of Nitrobacter populations in soil by Pcr. Applied and Environmental Microbiology 61(6), 2093-2098.

Feng, S., Xie, S., Zhang, X., Yang, Z., Ding, W., Liao, X., Liu, Y. and Chen, C. (2012) Ammonium removal pathways and microbial community in GAC-sand dual media filter in drinking water treatment. Journal of Environmental Sciences 24(9), 1587-1593.

Ferris, M.J., Muyzer, G. and Ward, D.M. (1996) Denaturing gradient gel electrophoresis profiles of 16S rRNA-defined populations inhabiting a hot spring microbial mat community. Applied and Environmental Microbiology 62(2), 340-346.

Francis, C.A., Roberts, K.J., Beman, J.M., Santoro, A.E. and Oakley, B.B. (2005) Ubiquity and diversity of ammonia-oxidizing archaea in water columns and sediments of the ocean. Proceedings of the National Academy of Sciences of the United States of America 102(41), 14683-14688.

Frey, S.D., Elliott, E.T. and Paustian, K. (1999) Bacterial and fungal abundance and biomass in conventional and no-tillage agroecosystems along two climatic gradients. Soil Biology \& Biochemistry 31(4), 573-585.

Graham, D.W., Knapp, C.W., Van Vleck, E.S., Bloor, K., Lane, T.B. and Graham, C.E. (2007) Experimental demonstration of chaotic instability in biological nitrification. Isme Journal 1(5), 385-393.

Gülay, A., Musovic, S., Albrechtsen, H.-J., Al-Soud, W.A., Sørensen, S.J., Smets, B.F., 2016. Ecological patterns, diversity and core taxa of microbial communities in groundwater-fed rapid gravity filters. ISME J. 
405

406

407

408

409

410

411

412

413

414

415

416

417

418

419

420

421

422

423

424

425

426

427

10, 2209-2222.

Gülay, A., Tatari, K., Musovic, S., Mateiu, R.V., Albrechtsen, H.-J. and Smets, B.F. (2014) Internal porosity of mineral coating supports microbial activity in rapid sand filters for groundwater treatment. Applied and Environmental Microbiology 80(22), 7010-7020.

Hagopian, D.S. and Riley, J.G. (1998) A closer look at the bacteriology of nitrification. Aquacultural Engineering 18(4), 223-244.

Hermansson, A. and Lindgren, P.E. (2001) Quantification of ammonia-oxidizing bacteria in arable soil by real-time PCR. Applied and Environmental Microbiology 67(2), 972-976.

Kasuga, I., Nakagaki, H., Kurisu, F., Furumai, H., 2010. Predominance of ammonia-oxidizing archaea on granular activated carbon used in a full-scale advanced drinking water treatment plant. Water Res. 44, 503949.

Kato, S., Chan, C., Itoh, T., Ohkuma, M., 2013. Functional Gene Analysis of Freshwater Iron-Rich Flocs at Circumneutral pH and Isolation of a Stalk-Forming Microaerophilic Iron-Oxidizing Bacterium. Appl.

Environ. Microbiol. 79, 5283-5290.

Koch, H., Galushko, A., Albertsen, M., Schintlmeister, A., Gruber-Dorninger, C., Lucker, S., Pelletier, E., Le Paslier, D., Spieck, E., Richter, A., Nielsen, P.H., Wagner, M., Daims, H., 2014. Growth of nitrite-oxidizing bacteria by aerobic hydrogen oxidation. Science (80-. ). 345, 1052-1054.

Lane, D.J. (1991) Nucleic acid techniques in bacterial systematics, pp. 115-175, John Wiley and Sons, New York.

LaPara, T.M., Wilkinson, K.H., Strait, J.M., Hozalski, R.M., Sadowksy, M.J. and Hamilton, M.J. (2015) The Bacterial Communities of Full-Scale Biologically Active, Granular Activated Carbon Filters Are Stable and Diverse and Potentially Contain Novel Ammonia-Oxidizing Microorganisms. Applied and Environmental Microbiology 81(19), 6864-6872. 
Lee, C.O., Boe-Hansen, R., Musovic, S., Smets, B., Albrechtsen, H.J. and Binning, P. (2014) Effects of dynamic operating conditions on nitrification in biological rapid sand filters for drinking water treatment. Water Research 64, 226-236.

Leininger, S., Urich, T., Schloter, M., Schwark, L., Qi, J., Nicol, G.W., Prosser, J.I., Schuster, S.C. and Schleper, C. (2006) Archaea predominate among ammonia-oxidizing prokaryotes in soils. Nature 442(7104), 806-809.

Lopato, L., Galaj, Z., Delpont, S., Binning, P.J. and Arvin, E. (2011) Heterogeneity of Rapid Sand Filters and Its Effect on Contaminant Transport and Nitrification Performance. Journal of Environmental Engineering-Asce 137(4), 248-257.

Lopato, L., Rottgers, N., Binning, P.J. and Arvin, E. (2013) Heterogeneous nitrification in a full-scale rapid sand filter treating groundwater. Journal of Environmental Engineering-Asce 139(3), 375-384.

Lytle, D.A., Sorg, T.J., Wang, L.L., Muhlen, C., Rahrig, M. and French, K. (2007) Biological nitrification in a full-scale and pilot-scale iron removal drinking water treatment plant. Journal of Water Supply Research and Technology-Aqua 56(2), 125-136.

Lytle, D.A., White, C., Williams, D., Koch, L. and Nauman, E. (2013) Innovative biological water treatment for the removal of elevated ammonia. Journal American Water Works Association 105(9), 87-88.

Martens-Habbena, W., Berube, P.M., Urakawa, H., de la Torre, J.R. and Stahl, D.A. (2009) Ammonia oxidation kinetics determine niche separation of nitrifying Archaea and Bacteria. Nature 461(7266), 976979.

Martens-Habbena, W., Berube, P.M., Urakawa, H., de la Torre, J.R., Stahl, D. a, 2009. Ammonia oxidation kinetics determine niche separation of nitrifying Archaea and Bacteria. Nature 461, 976-9.

Martens-Habbena, W. and Stahl, D.A. (2011) Nitrogen metabolism and kinetics of Ammonia-Oxidizing Archaea. Methods in Enzymology 496, 465-487. 
Martiny, A.C., Albrechtsen, H.J., Arvin, E. and Molin, S. (2005) Identification of bacteria in biofilm and bulk water samples from a nonchlorinated model drinking water distribution system: Detection of a large nitrite-oxidizing population associated with Nitrospira spp. Applied and Environmental Microbiology 71(12), 8611-8617.

Nitzsche, K.S., Weigold, P., Loesekann-Behrens, T., Kappler, A. and Behrens, S. (2015) Microbial community composition of a household sand filter used for arsenic, iron, and manganese removal from groundwater in Vietnam. Chemosphere 138, 47-59.

Niu, J., Kasuga, I., Kurisu, F., Furumai, H. and Shigeeda, T. (2013) Evaluation of autotrophic growth of ammonia-oxidizers associated with granular activated carbon used for drinking water purification by DNAstable isotope probing. Water Research 47(19), 7053-7065.

Palatinszky, M., Herbold, C., Jehmlich, N., Pogoda, M., Han, P., von Bergen, M., Lagkouvardos, I., Karst, S.M., Galushko, A., Koch, H., Berry, D., Daims, H., Wagner, M., 2015. Cyanate as an energy source for nitrifiers. Nature 524, 105-108.

Palomo, A., Jane Fowler, S., Gülay, A., Rasmussen, S., Sicheritz-Ponten, T., Smets, B.F., 2016.

Metagenomic analysis of rapid gravity sand filter microbial communities suggests novel physiology of Nitrospira spp. ISME J. 10, 2569-2581.

Pester, M., Maixner, F., Berry, D., Rattei, T., Koch, H., Lücker, S., Nowka, B., Richter, A., Spieck, E., Lebedeva, E., Loy, A., Wagner, M., Daims, H., 2014. NxrB encoding the beta subunit of nitrite oxidoreductase as functional and phylogenetic marker for nitrite-oxidizing $\mathrm{N}$ itrospira. Environ. Microbiol. $16,3055-3071$.

Pinto, A.J., Marcus, D.N., Ijaz, Z., Bautista-de los Santos, Q.M., Dick, G.J., Raskin, L., 2015. Metagenomic Evidence for the Presence of Comammox Nitrospira-Like Bacteria in a Drinking Water System. mSphere 1, e00054-15. 
Ririe, K.M., Rasmussen, R.P. and Wittwer, C.T. (1997) Product differentiation by analysis of DNA melting curves during the polymerase chain reaction. Analytical Biochemistry 245(2), 154-160.

Rittmann, B.E., Tang, Y., Meyer, K. and Bellamy, W.D. (2012) Water Treatment Plant Design. Association, A.W.W. (ed).

Rotthauwe, J.H., Witzel, K.P. and Liesack, W. (1997) The ammonia monooxygenase structural gene amoA as a functional marker: Molecular fine-scale analysis of natural ammonia-oxidizing populations. Applied and Environmental Microbiology 63(12), 4704-4712.

Sauder, L.A., Peterse, F., Schouten, S., Neufeld, J.D., 2012. Low-ammonia niche of ammonia-oxidizing archaea in rotating biological contactors of a municipal wastewater treatment plant. Environ. Microbiol. 14, 2589-2600.

Sharma, S.K., Petrusevski, B., Schippers, J.C., 2005. Biological iron removal from groundwater : a review. J. Water Supply Res. Technol. 54, 239-247.

Tatari, K., Smets, B.F. and Albrechtsen, H.J. (2016) Depth investigation of rapid sand filters for drinking water production reveals strong stratification in nitrification biokinetic behavior. Water Research.

Valentine, D.L. (2007) Adaptations to energy stress dictate the ecology and evolution of the Archaea. Nature Reviews Microbiology 5(4), 316-323.

van der Wielen, P.W.J.J., Voost, S., van der Kooij, D., 2009. Ammonia-oxidizing bacteria and archaea in groundwater treatment and drinking water distribution systems. Appl. Environ. Microbiol. 75, 4687-95.

van Kessel, M.A.H.J., Speth, D.R., Albertsen, M., Nielsen, P.H., Op den Camp, H.J.M., Kartal, B., Jetten, M.S.M. and Lucker, S. (2015) Complete nitrification by a single microorganism. Nature 528(7583), 555-559.

Verhamme, D.T., Prosser, J.I. and Nicol, G.W. (2011) Ammonia concentration determines differential growth of ammonia-oxidising archaea and bacteria in soil microcosms. Isme Journal 5(6), 1067-1071. 
496 White, C.P., DeBry, R.W. and Lytle, D.A. (2012) Microbial Survey of a Full-Scale, Biologically Active 497 Filter for Treatment of Drinking Water. Applied and Environmental Microbiology 78(17), 6390-6394.

498 Whitman, W.B., Coleman, D.C. and Wiebe, W.J. (1998) Prokaryotes: The unseen majority. Proceedings of 499 the National Academy of Sciences of the United States of America 95(12), 6578-6583.

500 Winkler, M.K.H., Bassin, J.P., Kleerebezem, R., Sorokin, D.Y. and van Loosdrecht, M.C.M. (2012) 501 Unravelling the reasons for disproportion in the ratio of AOB and NOB in aerobic granular sludge. Applied 502 Microbiology and Biotechnology 94(6), 1657-1666.

503 Wuchter, C., Abbas, B., Coolen, M.J.L., Herfort, L., van Bleijswijk, J., Timmers, P., Strous, M., Teira, E., 504 Herndl, G.J., Middelburg, J.J., Schouten, S. and Damste, J.S.S. (2006) Archaeal nitrification in the ocean. 505 Proceedings of the National Academy of Sciences of the United States of America 103(33), 12317-12322.

506 Zhang, Y., Love, N. and Edwards, M. (2009) Nitrification in drinking water systems. Critical Reviews in 507 Environmental Science and Technology 39(3), 153-208. 
510 Table 1. Selected water quality parameters and characteristics at the 4 investigated DWTPs.

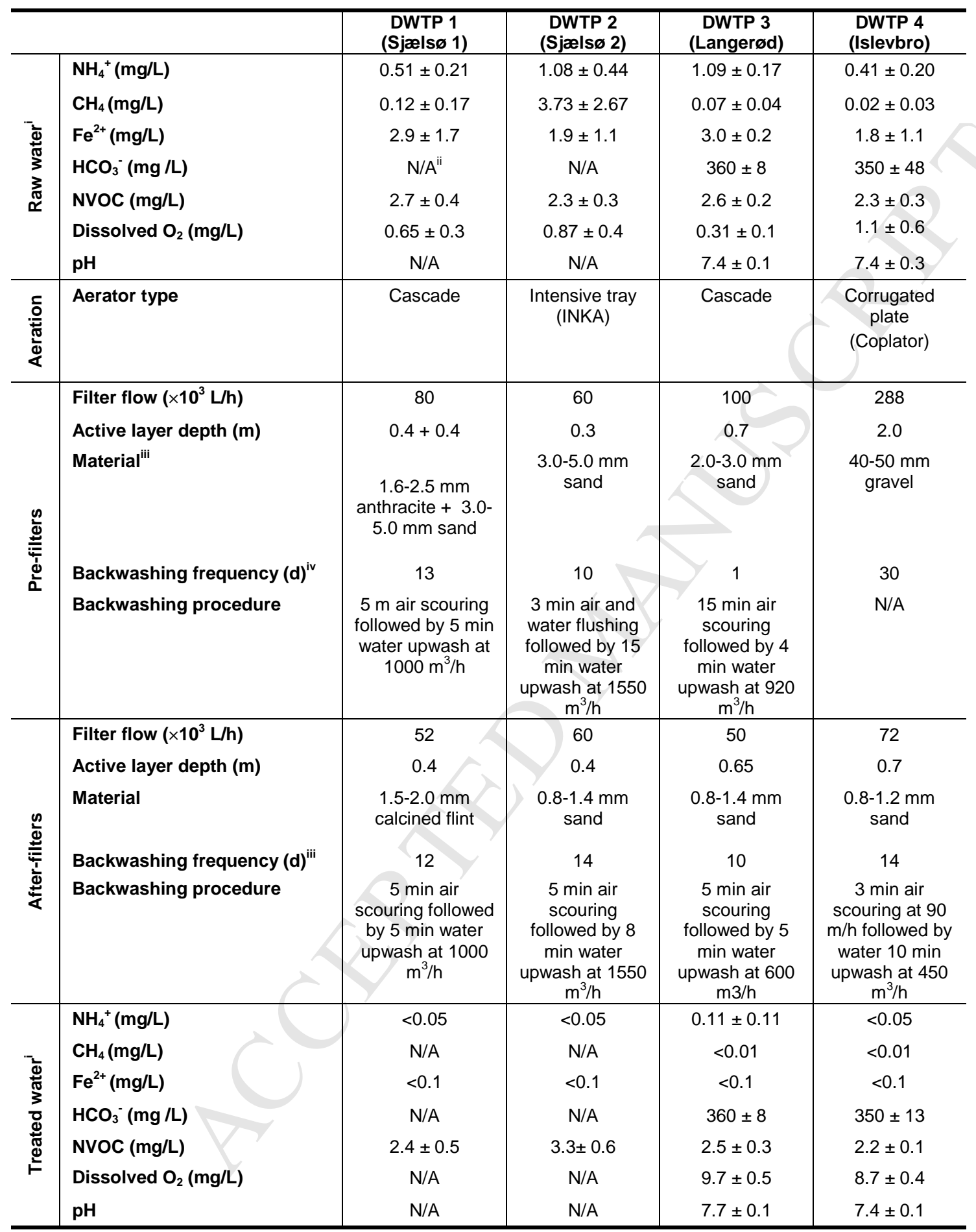

i. Water quality data are means provided by the DWTPS

ii. N/A: Not Available

iii. Nominal size range before filter start-up. Actual filter material size may be different due to mineral deposition on the filter material

iv. Backwashing frequency is regulated from the total filter flow. Calculation of average backwashing interval here is based on the average filter flow 
516 Table 2. Filter material bulk densities and microbial densities per mass and per volume of filter material.

517 Reported values are means calculated from equal weighing of measured values at all depths, sampling 518 locations in a filter and parallel filters at each DWTP. Mean values are reported with their standard deviation. 


\begin{tabular}{|c|c|c|c|c|c|c|}
\hline & \multicolumn{6}{|c|}{ Filter material bulk density } \\
\hline & \multicolumn{2}{|c|}{ Pre-filters } & & \multicolumn{2}{|c|}{ After-filters } & \\
\hline & \multicolumn{2}{|c|}{$\left(\times 10^{6} \mathrm{~g} / \mathrm{m}^{3}\right.$ filter material $)$} & $\mathbf{N}^{\mathrm{i}}$ & \multicolumn{2}{|c|}{$\left(\times 10^{6} \mathrm{~g} / \mathrm{m}^{3}\right.$ filter material $)$} & $\mathbf{N}^{\mathbf{i}}$ \\
\hline DWTP 1 & \multicolumn{2}{|c|}{$1.0 \pm 0.25$} & 6 & \multicolumn{2}{|c|}{$1.2 \pm 0.06$} & 12 \\
\hline DWTP 2 & \multicolumn{2}{|c|}{$1.4 \pm 0.04$} & 5 & \multicolumn{2}{|c|}{$1.5 \pm 0.03$} & 11 \\
\hline DWTP 3-E & \multicolumn{2}{|c|}{$1.7 \pm 0.05$} & 6 & \multicolumn{2}{|c|}{$1.6 \pm 0.05$} & 13 \\
\hline DWTP 3-W & \multicolumn{2}{|c|}{$1.5 \pm 0.07$} & 5 & \multicolumn{2}{|c|}{$1.6 \pm 0.05$} & 14 \\
\hline \multirow[t]{4}{*}{ DWTP 4} & \multicolumn{2}{|c|}{$\mathrm{N} / \mathrm{S}$} & - & \multicolumn{2}{|c|}{$1.5 \pm 0.28$} & 12 \\
\hline & \multicolumn{6}{|c|}{ Total bacteria (Eubacteria) $^{\mathrm{iii}}$} \\
\hline & Mass density & Volumetric density & $\mathbf{N}$ & Mass density & Volumetric density & $\mathbf{N}$ \\
\hline & $\left(\times 10^{9}\right.$ copies $\left./ g\right)$ & $\left(\times 10^{15}\right.$ copies $\left./ \mathrm{m}^{3}\right)$ & & $\left(\times 10^{9}\right.$ copies $\left./ g\right)$ & $\left(\times 10^{15}\right.$ copies $\left./ \mathrm{m}^{3}\right)$ & \\
\hline DWTP 1 & $2.0 \pm 1.0$ & $1.8 \pm 0.56$ & 6 & $0.9 \pm 2.2$ & $1.1 \pm 0.27$ & 29 \\
\hline DWTP 2 & $12 \pm 4.6$ & $16 \pm 6.1$ & 14 & $1.6 \pm 6.3$ & $2.5 \pm 0.97$ & 30 \\
\hline DWTP 3-E & $3.1 \pm 1.2$ & $5.1 \pm 2.0$ & 11 & $3.5 \pm 17$ & $5.7 \pm 2.9$ & 26 \\
\hline DWTP 3-W & $6.6 \pm 1.7$ & $9.8 \pm 2.7$ & 5 & $4.0 \pm 17$ & $6.5 \pm 2.8$ & 32 \\
\hline \multirow[t]{3}{*}{ DWTP 4} & $N / S^{v}$ & $\mathrm{~N} / \mathrm{S}$ & - & $8.8 \pm 13$ & $11 \pm 16$ & 40 \\
\hline & \multicolumn{6}{|c|}{ AOB (Nitrosomonas spp and Nitrosospira spp) ${ }^{\mathrm{iii}}$} \\
\hline & $\left(\times 10^{7}\right.$ copies $\left./ g\right)$ & $\left(\times 10^{13}\right.$ copies $\left./ \mathrm{m}^{3}\right)$ & & $\left(\times 10^{7}\right.$ copies $\left./ g\right)$ & $\left(\times 10^{13}\right.$ copies $\left./ \mathrm{m}^{3}\right)$ & \\
\hline DWTP 1 & $19 \pm 16$ & $16 \pm 12$ & 11 & $0.41 \pm 17$ & $0.49 \pm 0.21$ & 30 \\
\hline DWTP 2 & $13 \pm 6.5$ & $17 \pm 8.7$ & 14 & $2.0 \pm 0.88$ & $3.0 \pm 1.4$ & 30 \\
\hline DWTP 3-E & $5.8 \pm 4.2$ & $9.6 \pm 6.8$ & 11 & $15 \pm 14$ & $24 \pm 22$ & 26 \\
\hline DWTP 3-W & $23 \pm 7.8$ & $35 \pm 12$ & 5 & $12 \pm 12$ & $20 \pm 19$ & 25 \\
\hline \multirow[t]{3}{*}{ DWTP 4} & N/S & N/S & - & $1.2 \pm 2.3$ & $1.3 \pm 2.5$ & 35 \\
\hline & \multicolumn{6}{|c|}{ Nitrobacter ${ }^{\mathrm{jii}}$} \\
\hline & $\left(\times 10^{4}\right.$ copies $\left./ g\right)$ & $\left(\times 10^{10}\right.$ copies $\left./ \mathrm{m}^{3}\right)$ & 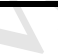 & $\left(\times 10^{4}\right.$ copies $\left./ g\right)$ & $\left(\times 10^{10}\right.$ copies $\left./ \mathrm{m}^{3}\right)$ & \\
\hline DWTP 1 & $7.8 \pm 1.5$ & $7.6 \pm 2.0$ & 12 & $3.0 \pm 1.8$ & $3.6 \pm 2.1$ & 12 \\
\hline DWTP 2 & $370 \pm 230$ & $500 \pm 310$ & 14 & $19 \pm 7.9$ & $29 \pm 12$ & 10 \\
\hline DWTP 3-E & $8.7 \pm 3.0$ & $15 \pm 4.9$ & 17 & $6.1 \pm 0.91$ & $10 \pm 15$ & 7 \\
\hline DWTP 3-W & $23 \pm 16$ & $34 \pm 23$ & 10 & $5.4 \pm 4.0$ & $8.6 \pm 6.3$ & 11 \\
\hline \multirow[t]{3}{*}{ DWTP 4} & N/S & $N / S$ & - & $9.7 \pm 16$ & $11 \pm 16$ & 36 \\
\hline & \multicolumn{6}{|c|}{ Nitrospira $^{\mathrm{iii}}$} \\
\hline & $\left(\times 10^{8}\right.$ copies $\left./ g\right)$ & $\left(\times 10^{14}\right.$ copies $\left./ \mathrm{m}^{3}\right)$ & & $\left(\times 10^{8}\right.$ copies $\left./ g\right)$ & $\left(\times 10^{14}\right.$ copies $\left./ \mathrm{m}^{3}\right)$ & \\
\hline DWTP 1 & $3.4 \pm 2.3$ & $3.8 \pm 3.4$ & 17 & $0.81 \pm 0.21$ & $0.97 \pm 0.26$ & 17 \\
\hline DWTP 2 & $24 \pm 13$ & $33 \pm 17$ & 15 & $3.3 \pm 1.1$ & $5.1 \pm 1.7$ & 25 \\
\hline DWTP 3-E & $1.7 \pm 0.88$ & $2.8 \pm 1.4$ & 10 & $5.2 \pm 4.1$ & $8.6 \pm 6.9$ & 23 \\
\hline DWTP 3-W & $5.9 \pm 0.85$ & $8.8 \pm 1.4$ & 5 & $8.9 \pm 5.4$ & $14 \pm 8.8$ & 23 \\
\hline \multirow[t]{3}{*}{ DWTP 4} & $\mathrm{~N} / \mathrm{S}$ & $\mathrm{N} / \mathrm{S}$ & - & $8.4 \pm 13$ & $9.7 \pm 14$ & 46 \\
\hline & & & AOA & & & \\
\hline & $\left(\times 10^{3}\right.$ copies $\left./ g\right)$ & $\left(\times 10^{9}\right.$ copies $\left./ \mathrm{m}^{3}\right)$ & & $\left(\times 10^{3}\right.$ copies $\left./ g\right)$ & $\left(\times 10^{9}\right.$ copies $\left./ \mathrm{m}^{3}\right)$ & \\
\hline DWTP 1 & $6.0 \pm 3.9$ & $5.7 \pm 3.3$ & 12 & $18 \pm 14$ & $21 \pm 17$ & 18 \\
\hline DWTP 2 & $15 \pm 11$ & $20 \pm 15$ & 14 & $3.8 \pm 1.7$ & $5.7 \pm 2.6$ & 15 \\
\hline DWTP 3-E & $2.3 \pm 1.1$ & $3.9 \pm 1.9$ & 17 & $<1^{\mathrm{vi}}$ & $<1.6^{\mathrm{vi}}$ & - \\
\hline DWTP 3-W & $2.6 \pm 2.5$ & $4.0 \pm 3.8$ & 5 & $<1^{\mathrm{vi}}$ & $<1.6^{\mathrm{vi}}$ & - \\
\hline DWTP 4 & $\mathrm{~N} / \mathrm{S}$ & N/S & - & $320 \pm 120$ & $460 \pm 260$ & 6 \\
\hline
\end{tabular}

i. Number of samples used to calculate mean density values

ii. Conversion from filter material mass to volume units was done by multiplying with the mean bulk density

iii. Quantified by $16 \mathrm{~S}$ rRNA targeted qPCR, iv. Quantified by amoA targeted qPCR

v. N/S: Not sampled due to coarse filter material in the pre-filter at DWTP 4

vi. Densities below detection limit 

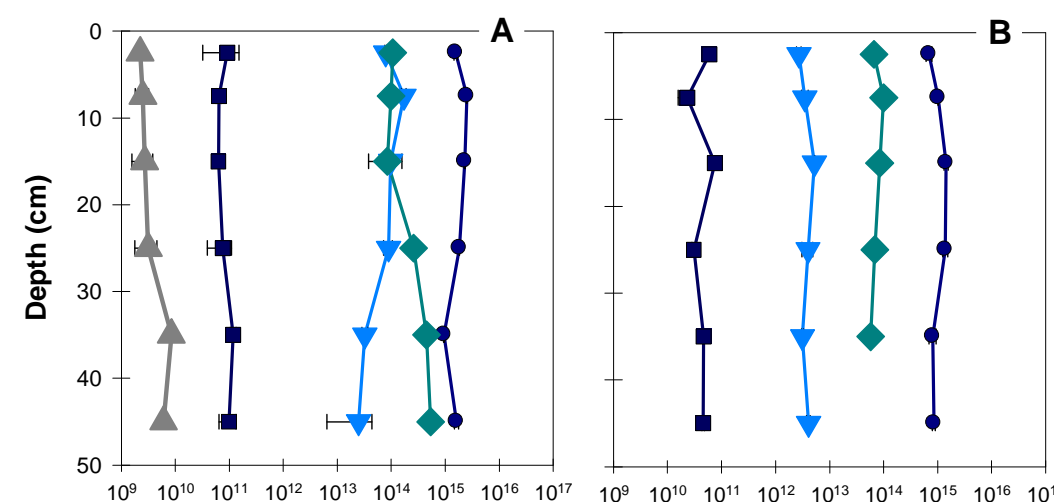

Copies $/ \mathrm{m}^{3}$

Copies $/ \mathrm{m}^{3}$

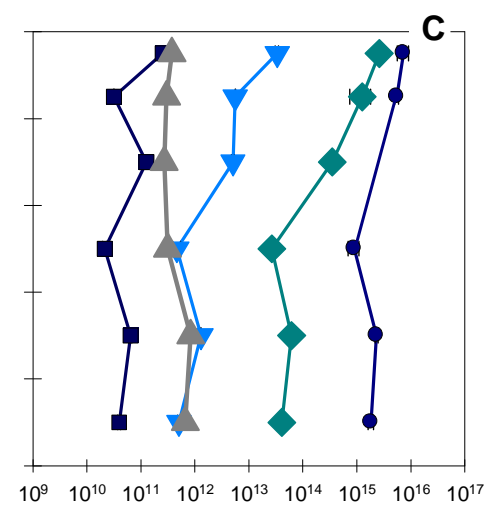

Copies $/ \mathrm{m}^{3}$

Figure 1. Depth profiles of the volumetric densities at one location of: one pre-filter at DWTP 1 (Panel A), one after-filter at DWTP 1 (Panel B) and one after-filter at DWTP 4 (Panel C). Densities were quantified by qPCR and error bars represent the standard deviation of the analytical method. 

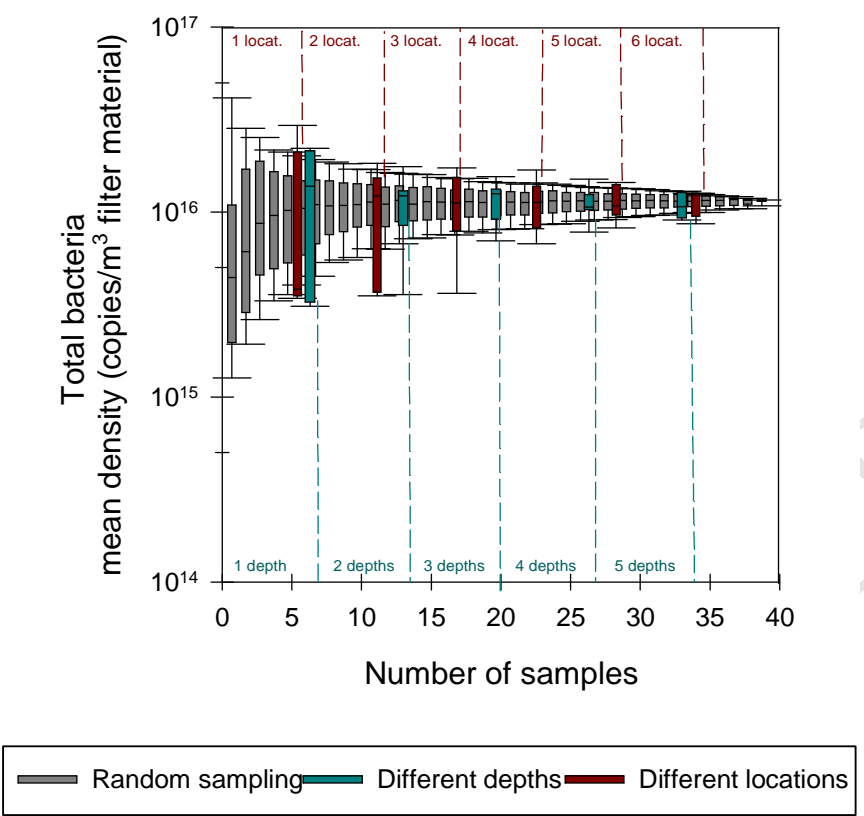

528 Figure 2. Distribution of total bacterial mean density at DWTP 4 based on sample number and sampling

529 strategy. Random sampling includes all random combinations of samples at different depths, locations and 530 parallel after-filters. Sampling at different depths includes all locations at these specific depths and sampling 531 at different locations includes all depths at these specific locations. 

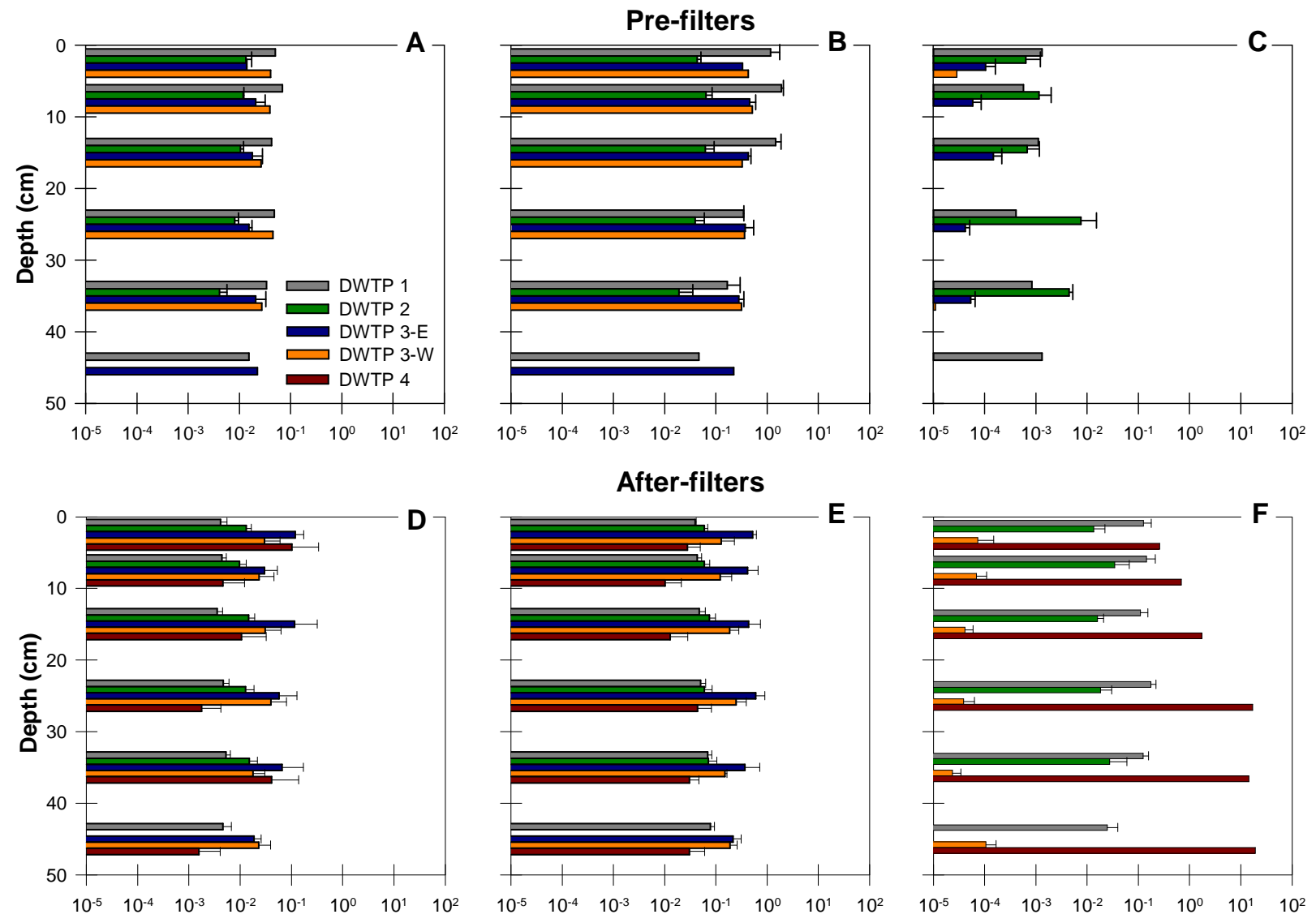

AOB/Total bacteria

AOB/Nitrospira

АOA/AOB

533 Figure 3. Density ratios in the pre-filters (Panels A-C) and after-filters (Panels D-F) at all investigated

534 DWTPs. Panels A and D: ratio of AOB to total bacteria quantified by $16 \mathrm{~S}$ rRNA-specific qPCR; Panels B

535 and E: ratio of AOB to Nitrospira quantified by 16S rRNA-specific qPCR; Panels C and F: ratio of AOA to

536 AOB quantified by the amoA-specific qPCR. Bars are means of all the sampled locations in all parallel

537 filters and error bars are the standard deviation of the mean. 
relative abundance

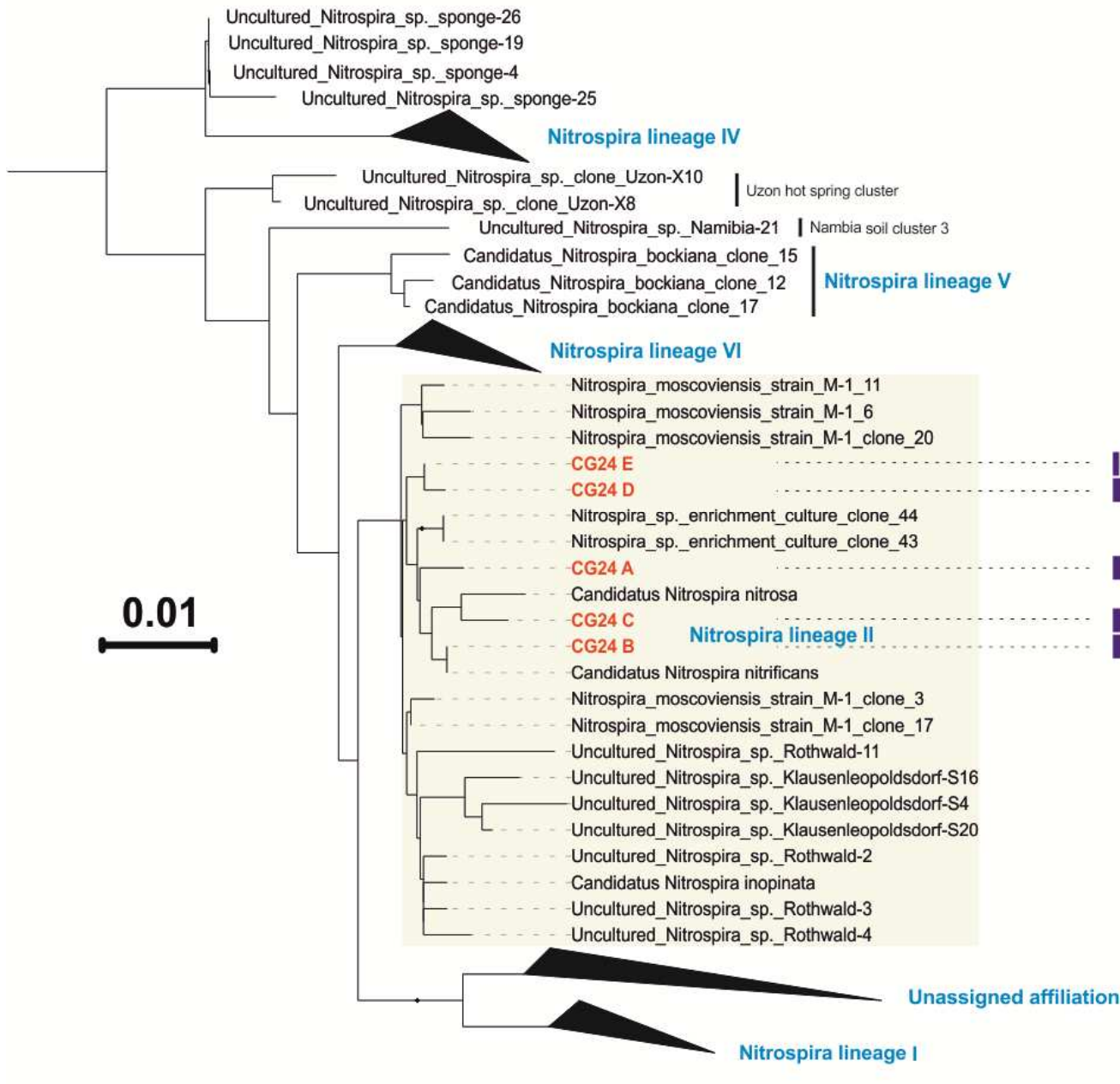

$n \times r$ B

After

16S rRNA lineage

relative abundance

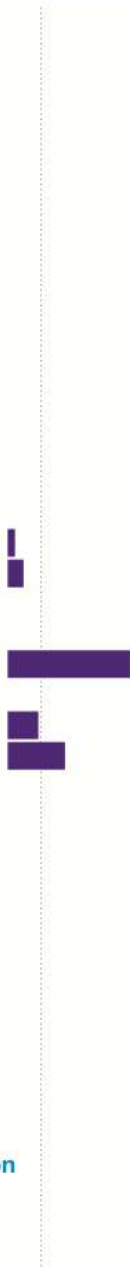

$5 \% \quad 20 \%$
Pre

After

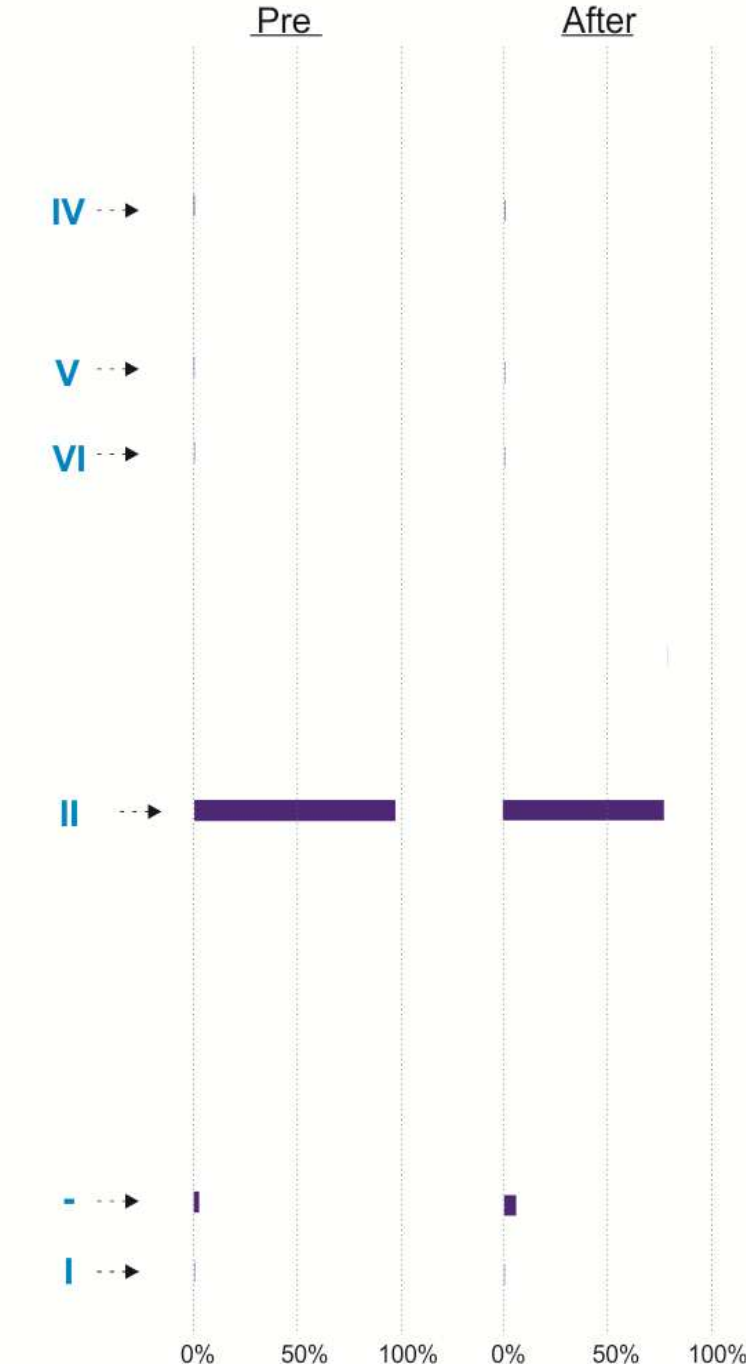


539 Figure 4. Phylogenetic analysis of $n x r B$ genes retrieved from the CG24 Nitrospira population genome 540 (Palomo et al., 2016) with NCBI database recorded sequences as reference (Pester et al., 2014). The scale bar 541 indicates $1 \%$ estimated sequence divergence. Relative abundance of CG24 nxrB genes (compared to total $542 n x r B$ gene in the community metagenome) and relative abundance of Nitrospira 16S rRNA sublineages 543 (compared to all Nitrospira sequences) sequences are reported. 

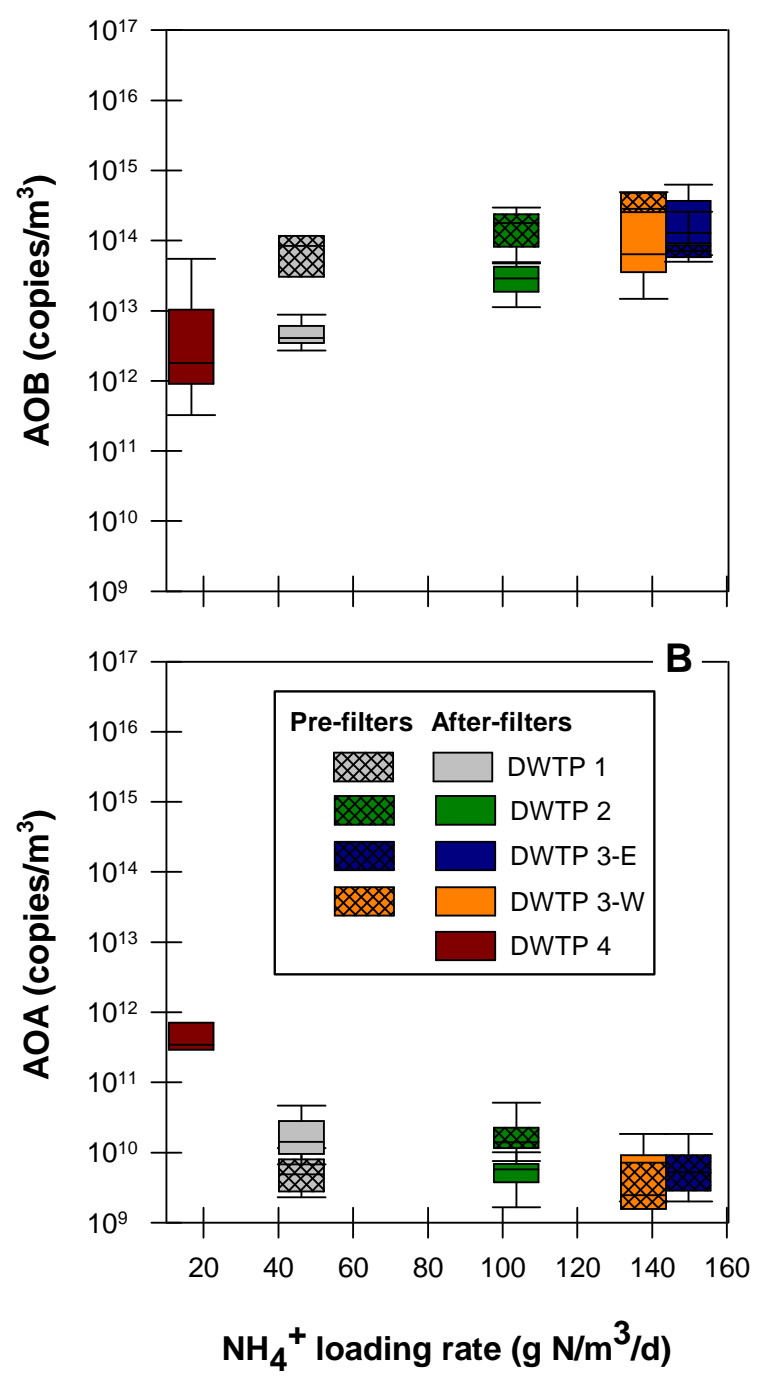

546

547 Figure 5. Volumetric densities of AOB (Panel A) and AOA (Panel B) in the investigated pre- and after548 filters as a function of the $\mathrm{NH}_{4}^{+}$loading rate to the DWTP. 


\section{Highlights}

- Microbial density in RSFs are high (upto $10^{9}$ to $10^{10}$ per gram $\left(10^{15}\right.$ to $10^{16}$ per $\left.\mathrm{m}^{3}\right)$ but vary spatially.

- Acceptable mean precision of density estimates requires 7 random samples.

- $\quad$ Nitrospira were more abundant than Nitrobacter and AOBs.

- Nitrospira abundance is likely caused by their $\mathrm{NH}_{4}{ }^{+}$oxidation capability (comammox).

- AOB consistently exceed AOAs in RSFs, except in RSFs with strong stratification. 